\title{
Small Signal Stability Analysis of Detailed DC Grids Network Model
}

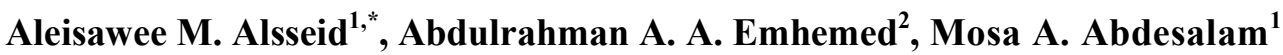 \\ ${ }^{1}$ College of Electronic Technology-Bani Walid, 38645 Bani Walid, Libya \\ ${ }^{2}$ College of Technical Sciences-Bani Walid, Libya
}

Copyright $\odot 2018$ by authors, all rights reserved. Authors agree that this article remains permanently open access under the terms of the Creative Commons Attribution License 4.0 International License

\begin{abstract}
DC grids based on VSC-HVDC could be a competitive and an attractive option for many applications such as renewable energy interconnection or for power supply to large metropolitan areas for many reasons. A detailed $121^{\text {st }}$ order multiple-input multiple output small-signal dynamic model of a DC grid network is presented in this paper. It contains control systems, and detailed representations of the AC and DC side. Aspects such as DC voltage droop control, the cut off frequency of the DC voltage feedback filters are discussed in detail. An eigenvalues stability study is used to find the optimum values of the droop gains and the cut off frequency of the DC voltage feedback filters. The model accuracy is verified using detailed PSCAD simulation. Testing on the detailed simulator PSCAD/EMTDC is carried out all over to validate the conclusions that obtained from analytical studies.
\end{abstract}

Keywords DC Network, DC Voltage Droop Control, Eigenvalues, Gain Selection, Modeling, Multiterminal HVDC, Stability

\section{Introduction}

High voltage direct current (HVDC) transmission based on Voltage Source Converters (VSC) has been implemented in many projects since 1996 and it is becoming accepted in power industry. Although all installations operate as 2-terminal systems, there has been significant interest for developing multiterminal VSC HVDC. VSC HVDC has some features like constant DC voltage and ability to connect to weak AC systems which make it suitable for developing multiterminal systems [1]. The stability studies of VSC HVDC are very important because of fast converter dynamics. The reported studies are focused on controller design using detailed simulation [2-4] or averaged analytical modeling [5]. The dynamic studies with analytical models can be very effective in understanding dynamic interactions between HVDC and the joining AC systems [6].

Advancing VSC HVDC to multi-terminal HVDC (M-VSC-HVDC) system brings advantages in many aspects such as control flexibility, reliability and economy [7-9]. M-VSC-HVDC can be an attractive alternative to $\mathrm{AC}$ transmission in urban areas where underground cable transmission is preferred for safety and environmental reasons [8]. These systems can be used for urban area interconnection and power quality improvement. A multiterminal VSC-HVDC system is becoming very attractive for interconnecting large offshore power parks [9-12]. DC cables are necessary in the offshore environment, and since in many locations in North Sea we have power parks with over $10 \mathrm{GW}$ potential, a M-VSC HVDC is better alternative to multiple, individual, radial HVDC links.

A DC grid is similar to M-VSC HVDC but it would involve meshed DC interconnections with multiple power flow paths. The DC network can be radial, meshed or a combination of both. The terminals would be connected to several points in synchronized/unsynchronized AC network.

The underlying principles for control and operation of DC grids are developed as an extension of 2-terminal control [9-13]. One DC terminal will regulate DC voltage and the remaining terminals will set the local DC current/power. However the current controlling terminals should also have a droop DC voltage feedback [14-17].

In the literature, there are many control schemes based on the conventional droop technique, and they have also been applied to several distributed resource controls [14-17]. Droop control is utilized to accomplish proper load sharing control of each independent distributed generation systems and is performed using locally measurable feedback signals [15]. Droop control as a solution to voltage regulation problems, reactive power oscillations was discussed [16]. All the above studies use essentially static design approach where DC droop gain is selected (typically around 10\%) and then impact on 
transient performance is analyzed. Reference [17] presents a design methodology for droop control based on frequency-response, however the system model is still overly simplified. A dynamic study is required in order to evaluate dynamic instabilities caused by droop gains and to examine possible negative interactions between terminals in a DC grid.

This paper studies a detailed analytical model for a DC grid which should have good accuracy within frequency range for main HVDC control loop, i.e. below $100 \mathrm{~Hz}$. This model will be used to study system control under a range of operating conditions on MATLAB. The DC droop gains and the associated filters will be selected based on the eigenvalue analysis for the overall DC grid PSCAD /EMTDC detailed model will be used for model verification and to prove the theoretical analysis of DC droop gains.

\section{DC Grid Test System}

The DC grid test system consists of five converters (VSC1-VSC5), two sending AC systems, and three equivalent receiving $\mathrm{AC}$ systems. The detail model of the studied network is shown in Fig. 1. Terminals T1 and T5 are connected to two sending AC grids, and the three terminals (T2, T3, and T4) are connected to different points in the receiving $\mathrm{AC}$ grid (large metropolitan area). Each AC system has its own equivalent impedance and Short-Circuit-Ratio (SCR) and all data are given in Table-A1 in the Appendix. The AC system voltages are labeled $\mathrm{V}_{\mathrm{ACT} 1}, \mathrm{~V}_{\mathrm{ACT} 2}, \mathrm{~V}_{\mathrm{ACT} 3}, \mathrm{~V}_{\mathrm{ACT} 4}, \mathrm{~V}_{\mathrm{ACT} 5}$. A $\Delta-\mathrm{Y}$ transformer is connected with its corresponding impedance to each terminal. A two-level PWM VSC using IGBT switches is employed. Two equally sized capacitors are connected across the DC terminals $\left(\mathrm{C}_{\mathrm{DCTn}}\right), \mathrm{n}=1,2, ., 5$ of converter with grounded midpoint. There are two main HVDC lines connecting sending area with receiving area (DC lines 1 and 4). The two sending terminals are also directly linked by a $200 \mathrm{~km}$ DC cable in order to improve system flexibility of operation and security of supply. The three receiving systems are also interlinked. In such configuration any DC cable be faulted, but the power will be undisrupted to all terminals assuming adequate fault isolation and rating of remaining components It is assumed that DC Circuit breakers are installed at the ends of each cable. The DC cable data are given in Table-A2.
Table A1. Five Terminals Test System Parameters

\begin{tabular}{|c|c|c|}
\hline \multicolumn{3}{|c|}{ TERMINAL FIVE TEST SYSTEM PARAMETERS } \\
\hline VSCT5 Rated Power & $P_{V S C T 5 \text { rated }}$ & $600 \mathrm{MW}$ \\
\hline $\mathrm{V}_{\mathrm{ACT5}}$ Rated Voltage & $V_{\text {ACTS rated }}$ & $220 \mathrm{KV}$ \\
\hline $\mathrm{AC}$ sy. Par, $\mathrm{V}_{\mathrm{ACT5}}(\mathrm{SCR}=10, \mathrm{X} / \mathrm{R}=10)$ & $L_{A C T S} / R_{A C T S}$ & $0.05 \mathrm{H} / 1.6 \Omega$ \\
\hline Transformer Parameters-T5 & $\begin{array}{c}S_{T 5 \text { rated }} / \\
L_{A C T 5}\end{array}$ & $\begin{array}{l}\text { 300MVa } \\
\text { /0.12p.u. }\end{array}$ \\
\hline DC capacitance & $C_{D C T S}$ & $40 \mathrm{uF}$ \\
\hline \multicolumn{3}{|c|}{ TERMINAL FOUR TEST SYSTEM PARAMETERS } \\
\hline VSCT4 Rated Power & $P_{\text {VSCT4rated }}$ & $300 \mathrm{MW}$ \\
\hline $\mathrm{V}_{\mathrm{ACT} 4}$ Rated Voltage & $V_{A C T 4 r a t e d}$ & $110 \mathrm{KV}$ \\
\hline VSCT4 Rated Power & $P_{\text {VSCTArated }}$ & 300MW \\
\hline $\begin{array}{c}\text { AC sy. Para, } \mathrm{V}_{\mathrm{ACT} 4}(\mathrm{SCR}=6.5, \\
\mathrm{X} / \mathrm{R}=10)\end{array}$ & $L_{A C T 4} / R_{A C T 4}$ & $0.019 \mathrm{H} / 0.6174 \Omega$ \\
\hline Transformer Parameters-T4 & $S_{\text {T4rated }} / L_{A C T 4}$ & $\begin{array}{l}\text { 300MVa } \\
\text { /0.12p.u. }\end{array}$ \\
\hline \multicolumn{3}{|c|}{ TERMINAL TTHREE TEST SYSTEM PARAMETERS } \\
\hline VSCT3 Rated Power & $P_{\text {VSCT3rated }}$ & $300 \mathrm{MW}$ \\
\hline $\mathrm{V}_{\mathrm{ACT} 3}$ Rated Voltage & $V_{A C T 3 \text { rated }}$ & $110 \mathrm{KV}$ \\
\hline AC sy. Para, $\mathrm{V}_{\mathrm{ACT2}}(\mathrm{SCR}=14, \mathrm{X} / \mathrm{R}=7)$ & $L_{A C T 3} / R_{A C T 3}$ & $0.009 \mathrm{H} / 0.40 \Omega$ \\
\hline Transformer Parameters-T3 & $\begin{array}{c}S_{T 3 \text { rated }} / \\
L_{A C T 3} \\
\end{array}$ & $\begin{array}{l}\text { 300MVa / } \\
0.12 \text { p.u. }\end{array}$ \\
\hline DC capacitance & $C_{D C T 3}$ & $40 \mathrm{uF}$ \\
\hline \multicolumn{3}{|c|}{ TERMINAL TWO TEST SYSTEM PARAMETERS } \\
\hline VSCT2 Rated Power & $P_{V S C T 2 r a t e d}$ & 300MW \\
\hline $\mathrm{V}_{\mathrm{ACT2}}$ Rated Voltage & $V_{\text {ACT2rated }}$ & $110 \mathrm{KV}$ \\
\hline $\mathrm{AC}$ sy. Para, $\mathrm{V}_{\mathrm{ACT} 2}(\mathrm{SCR}=10, \mathrm{X} / \mathrm{R}=5)$ & $L_{A C T 2} / R_{A C T 2}$ & $0.0125 \mathrm{H} / 0.8 \Omega$ \\
\hline Transformer Parameters-T2 & $\left|S_{T 2 \text { rated }} / L_{A C T 4}\right|$ & $\begin{array}{l}\text { 300MVa / } \\
0.12 \text { p.u. }\end{array}$ \\
\hline DC capacitance & $C_{D C T 4}$ & $40 \mathrm{uF}$ \\
\hline \multicolumn{3}{|c|}{ TERMINAL ONE TEST SYSTEM PARAMETERS } \\
\hline VSCT1 Rated Power & $P_{V S C T I \text { rated }}$ & 300MW \\
\hline $\mathrm{V}_{\mathrm{ACT2}}$ Rated Voltage & $V_{A C T 1}$ rated & $220 \mathrm{KV}$ \\
\hline $\mathrm{AC}$ sy. $\mathrm{Par}, \mathrm{V}_{\mathrm{ACT1}}(\mathrm{SCR}=10, \mathrm{X} / \mathrm{R}=10)$ & $L_{A C T I 2} / R_{A C T 1}$ & $0.051 \mathrm{H} / 1.604 \Omega$ \\
\hline Transformer Parameters-T1 & $\begin{array}{c}S_{T I \text { rated }} / \\
L_{A C T I} \\
\end{array}$ & $\begin{array}{l}\text { 300MVa / } \\
0.12 \text { p.u. }\end{array}$ \\
\hline DC capacitance & $C_{D C T 1}$ & $40 \mathrm{uF}$ \\
\hline
\end{tabular}

Table A2. DC cable parameters

\begin{tabular}{|c|c|}
\hline Length & $C_{D C L I} / L_{D C L I} / R_{D C L I}$ \\
\hline Line 4 (T5-T4) - 300 km & $52 \mu \mathrm{F} / 0.1 \mathrm{H} / 3 \Omega$ \\
\hline Line 3 (T3-T4) -60 km & $15.6 \mu \mathrm{F} / 0.03 \mathrm{H} / 0.86 \Omega$ \\
\hline Line 1 (T3-T2) $-40 \mathrm{~km}$. & $10.4 \mu \mathrm{F} / 0.02 \mathrm{H} / 0.604 \Omega$ \\
\hline Line 1 (T2-T1) - 200 km. & $78 \mu \mathrm{F} / 0.15 \mathrm{H} / 4.53 \Omega$ \\
\hline Line 1 (T1-T5) - 200 km. & $78 \mu \mathrm{F} / 0.15 \mathrm{H} / 4.53 \Omega$ \\
\hline
\end{tabular}




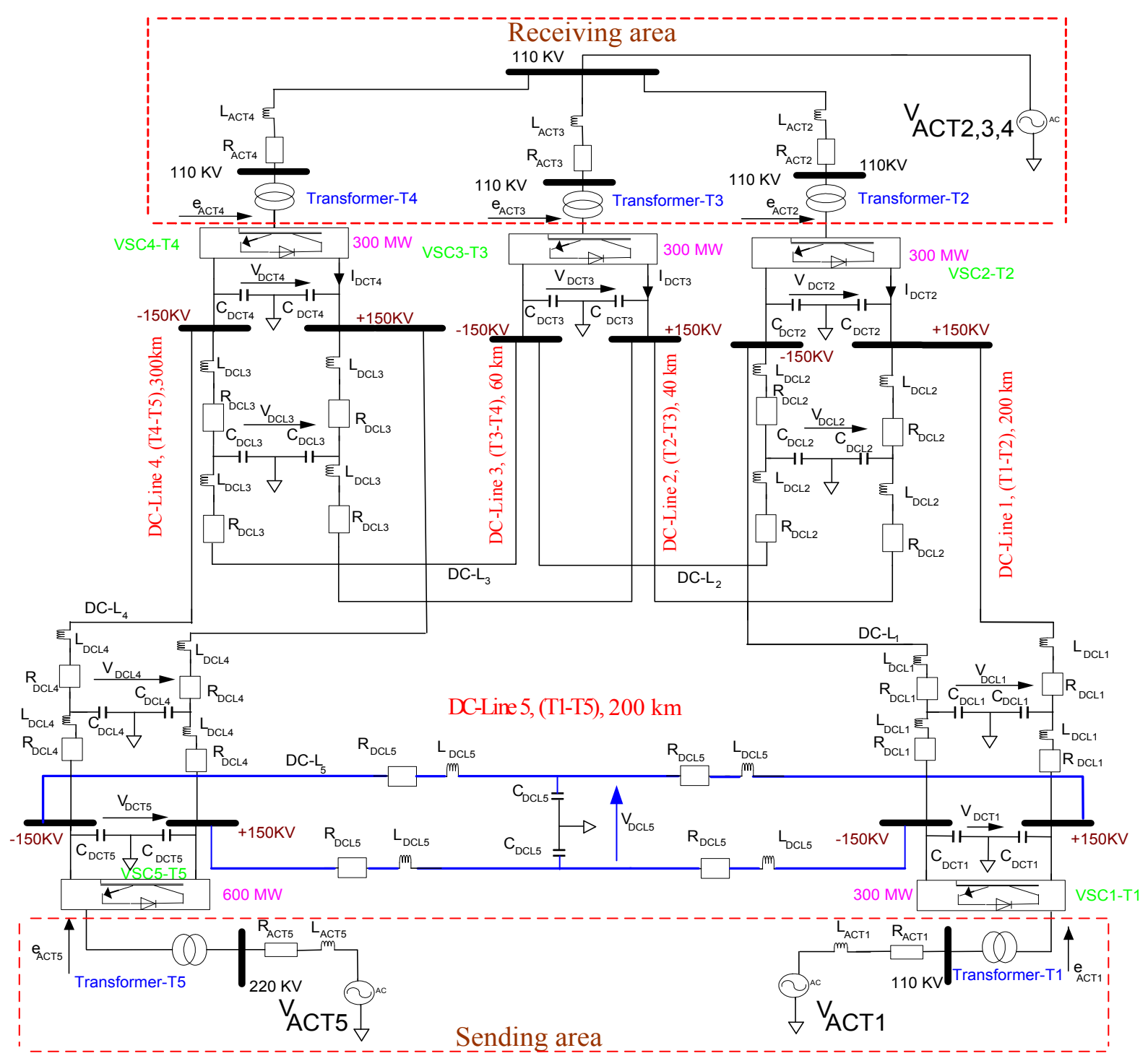

Figure 1. Detailed model of studied DC grids network

\section{DC Grid Control System}

The control strategy of each VSC converter is based on fast and decoupled inner current DQ control loops. The inner current control employs PID controllers as shown in figure 2. The outer control loops use AC voltage controller on $\mathrm{Q}$ axis, and $\mathrm{DC}$ voltage controller or DC current on D axis. In this DC grid, the d-axis current control with DC voltage droop control is implemented in the outer control at terminal four (T4), three (T3), two (T2) and one (T1). The droop control consists of droop gain $\mathrm{K}_{\mathrm{dcdroop}}$ and the second order filter. The terminal five (T5), as the large sending terminal, is adopted to control the DC voltage. The outputs of the control system $\left(M_{T 4 d}, M_{T 4 q}\right)$, after transformation, into magnitude $\left(M_{m T 4}\right)$ and phase shift $\left(M_{\varphi T 4}\right)$ represent the reference signals for the pulse-width modulation (PWM). The phase looked loop is used to synchronize the converter phase shift with the AC system. The DC voltage reference ( $\left.\mathrm{V}_{\mathrm{DC} \text { T4dref }}\right)$ is supplied by the operator. The terminal $\mathrm{T} 5$ has same control structure but it uses DC voltage control without droop. 


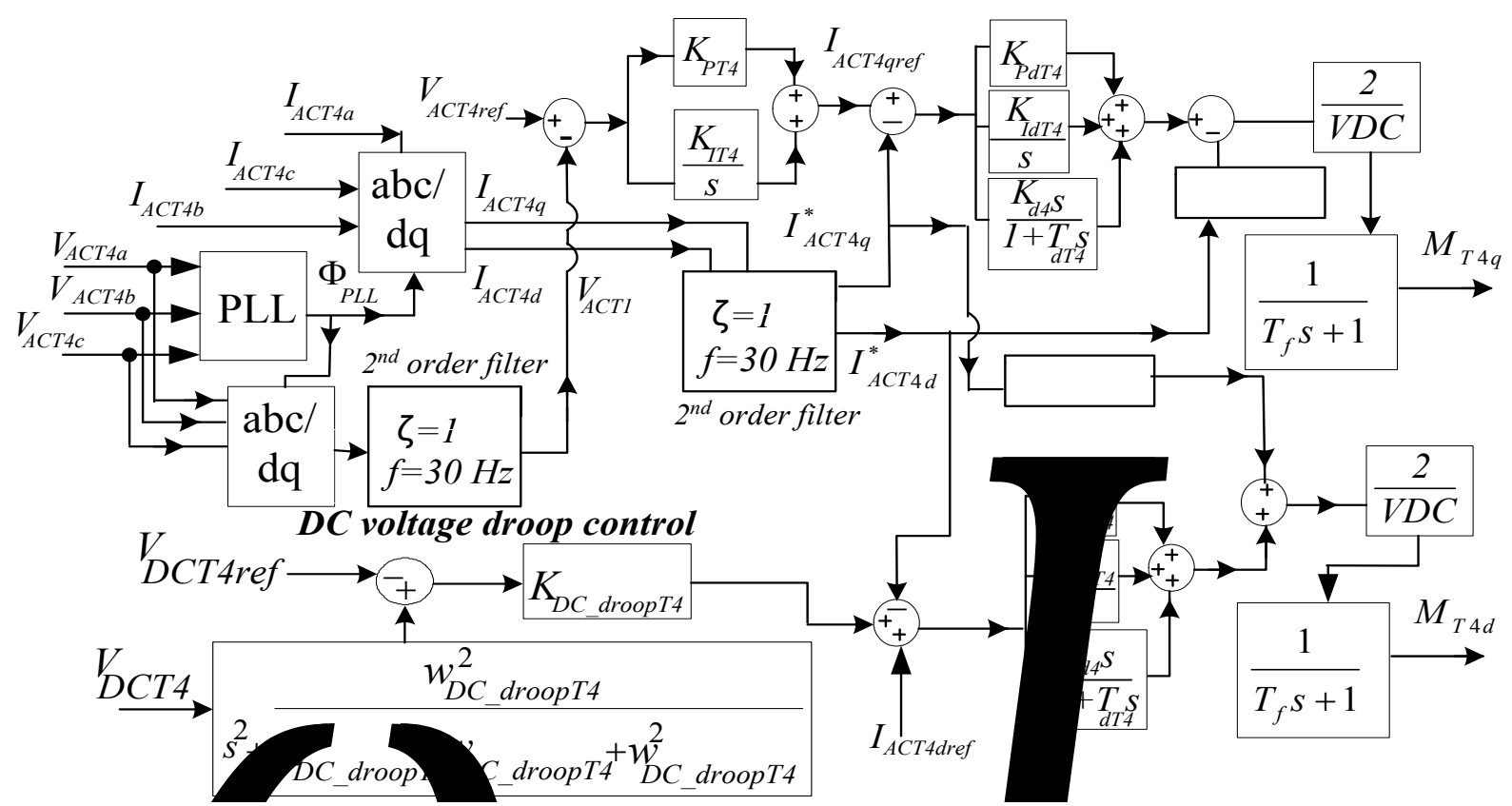

Figure 2. Control diagram of terminal four using d-axis current with DC voltage droop control and AC voltage

\section{Analytical Model}

\section{A. Model structures}

An accurate analytical modeling facilitates eigenvalue studies that would otherwise not be possible with conventional time-domain modeling approaches. The simulation on averaged analytical model is very fast regardless of the model size. An analytical model is developed by writing differential equations for all dynamic elements and then connecting various variables with static equations typically derived from power balance expressions. The equations are then linearised and the model is represented in state-space form. The DC grid detailed analytical modeling follows the similar principles reported with 2-terminal HVDC [5]. The modular approach is used for each of the 5 terminals in order to simplify development and provide flexibility for further expansion. Each of the terminals consists of: AC grid model, DC line model, converter model, controller and phase locked loop model and interlinking equations. Each variable in the model has equivalent physical representation.

\section{B. AC System model}

The equations describing the AC circuit ACT4 stated in a $d q$ reference frame synchronously rotating with the local PCC AC voltage vector $\left(V_{A C T 4}\right)$ are:

$$
\begin{aligned}
& L_{A C T 4 d} \frac{d}{d t} I_{A C T 4 d}=-V_{A C T 4 d}-R_{A C T 4} I_{A C T 4 d}+ \\
& +\omega L_{A C T 4} I_{A C T 4 q}+\frac{1}{2} M_{A C T 4 d} V_{D C T 4}
\end{aligned}
$$

$$
\begin{gathered}
L_{A C T 4 q} \frac{d}{d t} I_{A C T 4 q}=-V_{A C T 4 q}-R_{A C T 4} I_{A C T 4 q}+ \\
+\omega L_{A C T 4} I_{A C T 4 d}+\frac{1}{2} M_{A C T 4 q} V_{D C T 4} \\
p_{A C T 4}=\frac{3}{2}\left(V_{A C T 4 d} \cdot I_{A C T 4 d}+V_{A C T 4 q} \cdot I_{A C T 4 q}\right) \\
Q_{A C T 4}=\frac{3}{2}\left(V_{A C T 4 q} \cdot I_{A C T 4 d}-V_{A C T 4 q} \cdot I_{A C T 4 q}\right)
\end{gathered}
$$

where $V_{D C T 4}$ is the DC voltage at VSCT4, $R_{A C T 4}$ represents AC grid resistance and converter losses, $L_{A C T 4}$ is AC sysem inductance including transformer leakage inductance, $I_{A C T 4 d}$ and $I_{A C T 4 q}$ are AC dq current components at ACT4, $\omega$ is the frequency of the AC system and $P_{A C T 4} / Q_{A C T 4}$ is the active and reactive power at the PCC bus. The VSCT4 reference frame is aligned with the $V_{A C T 4}$ voltage vector employing a Phase Locked Loop, such that $V_{A C T 4 q}=0$, and $V_{A C T 4 d}=\left|v_{A C T 4}\right|$. Accordingly, the active and reactive power is controlled by independently controlling the AC current vector components using modulation control signals $\left(M_{T l d}, M_{T l q}\right)$.

\section{Converter model}

The linking between DC and AC voltages is achieved with the following linearized fundamental converter equations [5]:

$$
\begin{aligned}
\Delta V_{A C T 4 d} & =\frac{1}{2} M_{T 4 d}^{\circ} \Delta V_{D C T 4}+\frac{1}{2} \stackrel{\circ}{V}_{D C T 4} \Delta M_{T 4 d} \\
\Delta V_{A C T 4 q} & =\frac{1}{2} M_{T 4 q}^{\circ} \Delta V_{D C T 4}+\frac{1}{2} V_{D C T 4}^{\circ} \Delta M_{T 4 q}^{\circ}
\end{aligned}
$$


Therefore the converter is represented as linear continuous system in this model. The linking between AC and DC converter currents is similarly achieved by combining fundamental converter voltage equations, with $\mathrm{AC} / \mathrm{DC}$ power balance equations:

$$
\begin{aligned}
\Delta I_{D C T 4} & =-\frac{3}{4} \frac{1}{C_{D C T 4}} \stackrel{\circ}{I}_{A C T 4 d} \Delta M_{T 4 d}-\frac{3}{4} \frac{1}{C_{D C T 4}} \stackrel{\circ}{I}_{A C T 4 q} \Delta M_{T 4 q} \\
& -\frac{3}{4} \frac{1}{C_{D C R}} \stackrel{\circ}{M}_{T 4 d} \Delta I_{A C T 4 d}-\frac{3}{4} \frac{1}{C_{D C T 4}} \stackrel{\circ}{M}_{T 4 q} \Delta I_{A C T 4 q}
\end{aligned}
$$

\section{Final model}

Each terminal model has around 20-25 states and it is represented in state-space form. A $121^{\text {st }}$ order multiple-input multiple-output (MIMO) small-signal model of DC network based on 5 VSC converters and controls is then assembled in state-space form within MATLAB. The model consists of the following two interlinked sub-system state space models: DC system model including (DC-cables, Control systems, and PLL models), (106 ${ }^{\text {th }}$ order) and AC system model (terminals 1-5), $\left(15^{\text {th }}\right.$ order $)$. The input and output variables of the sub-systems are conditioned using linking matrices $\left(\mathbf{L}_{\mathrm{DCT}}\right.$, $\left.\mathbf{H}_{\mathrm{ACTn}}\right), \mathrm{n}=1, . .5$ that are developed using converter fundamental frequency modeling equations (5-7) and a range of other equations for converting variables.. The state-space model of the DC grid network is written in standard matrix form as:

$$
\begin{aligned}
& \dot{x}_{s}=\mathbf{A}_{s} \cdot \mathbf{x}_{s}+\mathbf{B}_{r e f} \mathbf{u}_{r e f} \\
& \mathbf{Y}_{s}=\mathbf{C}_{s} \cdot \mathbf{x}_{s}+\mathbf{D}_{r e f} \mathbf{u}_{r e f}
\end{aligned}
$$

where the system matrix $\left(\mathbf{A}_{\mathrm{s}}\right)$ incorporates the sub-system and linking matrices:

$$
\begin{gathered}
\mathbf{A}_{s}=\left[\begin{array}{ccc}
\mathbf{A}_{D C} & \mathbf{B}_{D C T 5} \mathbf{H}_{A C T 5} \mathbf{C}_{A C T S d q} & \mathbf{B}_{D C T 4} \mathbf{H}_{A C T 4} \mathbf{C}_{A C T 4 d q} \\
\mathbf{B}_{A C T 5} \mathbf{L}_{D C T 5} \mathbf{C}_{D C T 5} & \mathbf{A}_{A C d q T 5} & 0 \\
\mathbf{B}_{A C T 4} \mathbf{L}_{D C T 4} \mathbf{C}_{D C T 4} & 0 & \mathbf{A}_{A C d q T 4} \\
\mathbf{B}_{A C T 3} \mathbf{L}_{D C T 3} \mathbf{C}_{D C T 3} & 0 & 0 \\
\mathbf{B}_{A C T 2} \mathbf{L}_{D C T 2} \mathbf{C}_{D C T 2} & 0 & 0 \\
\mathbf{B}_{A C T 1} \mathbf{L}_{D C T 1} \mathbf{C}_{D C T 1} & 0 & 0 \\
\mathbf{B}_{D C T 3} \mathbf{H}_{A C T 3} \mathbf{C}_{A C T 3 d q} & \mathbf{B}_{D C T 2} \mathbf{H}_{A C T 2} \mathbf{C}_{A C T 2 d q} & \mathbf{B}_{D C T 1} \mathbf{H}_{A C T 1} \mathbf{C}_{A C T 1 d q} \\
0 & 0 & 0 \\
0 & 0 & 0 \\
\mathbf{A}_{A C d q T 3} & 0 & 0 \\
0 & \mathbf{A}_{A C d q T 2} & 0 \\
0 & 0 & \mathbf{A}_{A C d q T 1}
\end{array}\right]
\end{gathered}
$$

and the state vector $\left(\mathbf{x}_{\mathbf{s}}\right)$ incorporates all sub-system states, the input matrix $\left(\mathbf{B}_{\mathrm{s}}\right)$ incorporates all sub-system external input matrices, and the input vector $\left(\mathbf{u}_{\mathrm{s}}\right)$ incorporates all external inputs, as:

$$
\mathbf{x}_{S}=\left[\begin{array}{c}
x_{D C} \\
x_{A C T 5 d q} \\
x_{A C T 4 d q} \\
x_{A C T 3 d q} \\
x_{A C T 2 d q} \\
x_{A C T 1 d q}
\end{array}\right], \mathbf{B}_{S}=\left[\begin{array}{c}
B_{D C} \\
B_{A C T 5 d q} \\
B_{A C T 4 d q} \\
B_{A C T 3 d q} \\
B_{A C T 2 d q} \\
B_{A C T 1 d q}
\end{array}\right] \text { and } \mathbf{u}_{s}=\left[\begin{array}{c}
V_{D C T S r e f} \\
V_{A C T 5 r e f} \\
V_{A C T 4 r e f} \\
I_{A C T 4 d r e f} \\
V_{A C T 3 r e f} \\
I_{A C T 3 \text { dref }} \\
V_{A C T 2 \text { ref }} \\
I_{A C T 2 d r e f} \\
V_{A C T 1 r e f} \\
I_{A C T 1 \text { dref }}
\end{array}\right]
$$

And where the output vector $\left(\mathbf{Y}_{\mathrm{s}}\right)$ incorporates the outputs states, and the output matrix $\left(\mathbf{C}_{\mathrm{s}}\right)$ incorporates all sub-system output matrices as:

$$
\left[\begin{array}{cccccc}
C_{D C} & 0 & 0 & 0 & 0 & 0 \\
0 & C_{A C T 5} & 0 & 0 & 0 & 0 \\
0 & 0 & C_{A C T 4} & 0 & 0 & 0 \\
0 & 0 & 0 & C_{A C T 3} & 0 & 0 \\
0 & 0 & 0 & 0 & C_{A C T 2} & 0 \\
0 & 0 & 0 & 0 & 0 & C_{A C T 1}
\end{array}\right]
$$

\section{Model Validation}

A detailed DC grid model is developed on PSCAD platform. It includes detailed 6-swicth converter models with PWM control assuming frequency modulation index of $27\left(f_{s}=1350 \mathrm{~Hz}\right)$ at each terminal. Because of complexity, the PSCAD model is extremely slow but it has high accuracy. Also PSCAD only supports trial and error and gain tuning is very time-consuming. Fig. 3 shows system responses for a $10 \%$ reference step on VACT4 from PSCAD model and MATLAB analytical model. Figure 3a) confirms that the analytical model accurately represents Q-axis variables. Figure $3 b$ ) shows that the interaction with variables on $\mathrm{D}$ axis is accurate. Figure $3 \mathrm{c}$ ) confirms that the interactions with other terminals are accurate. We have further tested many other variable and in general matching is excellent. The validation confirms suitability of the analytical model for a wide range of multivariable dynamics studies and advanced control design for DC gird network. 


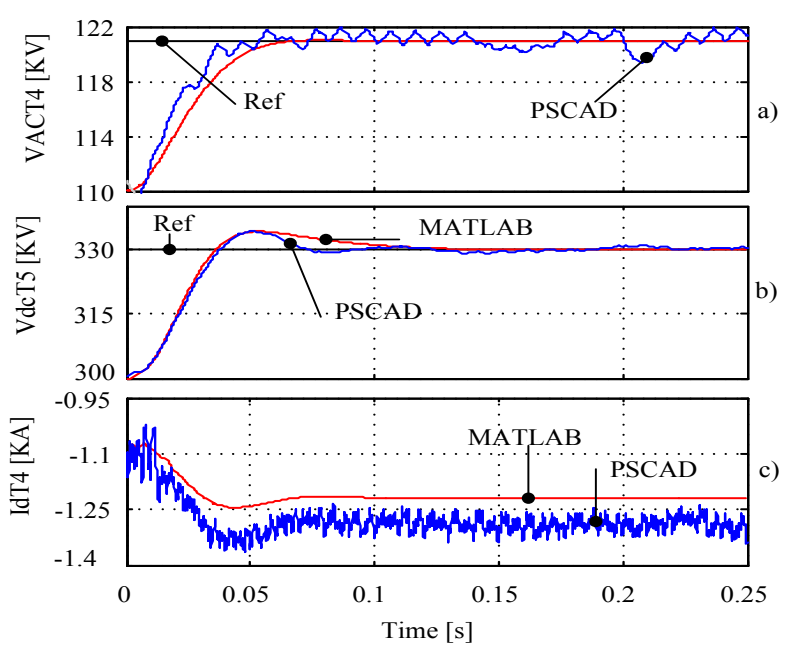

Figure 3. Analytical model verification against detailed non-linear PSCAD model, for a $10 \%$ step change on the ACT4 voltage reference. a) AC volate at terminal four VACT4 four, b). DC voltage at terminal four, c). Direct VSCT4 current $\left(\mathrm{I}_{\mathrm{ACdT}}\right.$ ), (Use just one step in this figure but show three variables as above),

\section{DC Grid Stability Study}

The controllers at individual terminals are tuned independently, ie assuming an equivalent DC source or DC current injection. The controller data are given Table-A3. This section is concentrated on the following objectives: a). to select optimum DC voltage droop control gains, b). study the influence of the selected gain on the other terminals, and c). optimum cutoff frequency of the DC voltage droop control filter. The analytical small-signal MATLAB model will be used to analyze the system stability and to select the values of the DC voltage droop control gains. A root-locus analysis is used for tuning the DC voltage droop gains and the PSCAD simulation is employed for final testing of the gains.

Table-A3. Five Terminals Control Parameters

\begin{tabular}{|c|c||c|c|}
\hline \multicolumn{2}{|c||}{ T4-CO. PARM. } & \multicolumn{2}{c|}{ T3-CO. PARM. } \\
\hline$K_{P T 4}$ & 0.0195 & $K_{P I T 3}$ & 0.00795 \\
\hline$K_{I I}$ & 6.5 & $K_{I I T 3}$ & 10.5 \\
\hline$K_{d T 4}$ & 0.11 & $K_{d T 3}$ & 0.11 \\
\hline$K_{P 22 T 4}$ & 15 & $K_{P 22 T 3}$ & 15 \\
\hline$K_{I 22 T 4}$ & 500 & $K_{I 22 T 3}$ & 500 \\
\hline$T_{d T 4}$ & 0.02 & $T_{d t 3}$ & 0.02 \\
\hline \multicolumn{2}{|c|}{ T2-CO. PARM. } & \multicolumn{2}{|c|}{ T1-CO. PARM. } \\
\hline$K_{P I T 2}$ & 0.0195 & $K_{P I T 1}$ & 0.0195 \\
\hline$K_{I I T 2}$ & 9.5 & $K_{I I T 1}$ & 6.5 \\
\hline$K_{d T 2}$ & 0.11 & $K_{d T 1}$ & 0.11 \\
\hline$K_{P 22 T 2}$ & 95 & $K_{P 22 T 1}$ & 95 \\
\hline$K_{I 2 T 2}$ & 1000 & $K_{I 22 T 1}$ & 1000 \\
\hline$T_{d T 2}$ & 0.01 & $T_{d T 1}$ & 0.01 \\
\hline \multicolumn{2}{|c|}{ T5-CO. PARM. } \\
\hline$K_{P I T 5}$ & 0.00932 & $K_{d T 5}$ & 0.11 \\
\hline$K_{I I T 5}$ & 2.5 & $K_{P 22 T 5}$ & 100 \\
\hline$K_{P 2 T 5}$ & 0.0075 & $K_{I 22 T 5}$ & 1000 \\
\hline$K_{I I T 5}$ & 0.5 & $T_{d T 5}$ & 0.01 \\
\hline
\end{tabular}

With reference to the Fig. 2 the initial values for the droop control filter (the frequency $\omega_{D C \_ \text {droopT4 }}=2 * \pi * f_{D C \_d r o o p T 4}$, where $f_{D C \_ \text {droopT4 }}$ is the cutoff frequency and the damping factor $\xi_{D C_{-} \text {droopT4 }}$ ) are assumed as follows $f_{D C_{-} \text {droopT4 }}=30 \mathrm{~Hz}$, and $\xi_{D C_{-} \text {droopT4 }}=1$ The value of DC voltage droop gain $\left(K_{D C \text { droopT4 }}\right)$ is varied. The DC droop gains are adjusted sequentially: Terminal,4, Terminal 3, Terminal 2 and Terminal 1. Note that tuning first terminal, terminal 4 involves all other droop gains disabled, but tuning last gain at terminal 1 involves all other gains enabled. Because of the limited space, only two terminals are presented, terminal four (inverter) and terminal one (rectifier).

\section{A. Selection of de voltage droop controller at terminal four (receiving area)}

The root-locus of the overall (5-terminal) system matrix in (10) is studied with changes in $K_{D C_{-} \text {droopT4 }}$ and with fixed cutoff frequency (initially assumed at $f_{D C_{-} \text {droopT4 }}=30 \mathrm{~Hz}$ ) The root-locus is shown in Fig. 4 for an increase in the value of $K_{D C}$ droopT4 from $0-0.08$ to 0 In this figure, the maximum value of DC droop gain is denoted by a diamond $(\diamond)$, selected value marked by circle (o), and the minimum value marked by an asterisk $(*)$. In the static design approach, the droop gain is described by the following equation [89], [9]:

$$
K_{D C_{-} \text {droop T4 }}=\frac{\Delta I_{\text {DCrated_T4 }}}{\Delta V_{\text {DCrated_T4 }_{-}}}
$$

where $\Delta \mathrm{V}_{\text {DCrated_T4pu }}$ is per unit maximum variation of $\mathrm{DC}$ voltage and $\mathrm{I}_{\text {DCrated_T4 }}$ is per unit rated DC current of terminal four. Typically per unit DC droop is $5 \%-20 \%$ [8], [9]. Figure 4 shows that as the DC droop gain is increased eigenvalues on branch ' $a$ ' are moved in the left half of the s-plane. On the contrary, branch ' $b$ ' crosses the imaginary axis into unstable region and branches 'c, d, e' are moved towards the right-half plane. It is evident that the system stability is improved only for limited range of small droop gain, whereas for very high gains the eigenvalues move towards unstable region making the system more oscillatory and ultimately the system is unstable. Thus the optimum value of the DC voltage droop gain is chosen as marked by the circle (o), $\mathrm{K}_{\mathrm{dc} \_ \text {droopT4 }}=$ 0.025 , correspondingto $\mathrm{K}_{\mathrm{DC} \_ \text {drooppu }}=\mathrm{I}_{\mathrm{dcT} 4} /\left(\mathrm{V}_{\mathrm{dcT} 4} * \mathrm{~K}_{\mathrm{DC} \_ \text {droopT4 }}\right)$ $=13.3 \%$. The influence of the cutoff frequency of the DC voltage droop filter at terminal 4 is considered next assuming the selected DC droop gain $\left(K_{D C}\right.$ droopT4 $\left.=-0.025\right)$ Fig. 5 shows the root locus considering a variation of $f_{D C \text { droopT4 }}$ from zero $\mathrm{Hz}$ to $500 \mathrm{~Hz}$. In general all branches improve stability except branch "a" which worsens stability for increased cut-off frequency. The final value of the $f_{D C \_ \text {droopT4 }}$ is selected as $30 \mathrm{~Hz}$. With the same procedure the impact of the DC voltage droop gains at terminals three and two are studied. It is established that with an adequate stability margin the selected optimal gains are identical to 
those are obtained from Figures 4 and 5. The final selected gains are presented in Table-A4.

Table-A4. The selection of DC voltage droop control parameters at terminal one

\begin{tabular}{|c|c|}
\hline DC droop gain & Cutoff frequency \\
\hline$K_{D C_{d} \_r o o p T 4}=-0.025(13.3 \%)$ & $f_{D C_{-} \text {droop T4 }}=30 \mathrm{~Hz}$ \\
\hline$K_{D C \_ \text {droop } T 3}=-0.025(13.3 \%)$ & $f_{D C \_ \text {droop T3 }}=30 \mathrm{~Hz}$ \\
\hline$K_{D C_{d} \text { droop } T 2}=-0.025(13.3 \%)$ & $f_{D C_{-} \text {droop T2 }}=30 \mathrm{~Hz}$ \\
\hline$K_{D C \_d r o o p T 1}$, varied & $f_{D C_{-} \text {droopTI }}=30 \mathrm{~Hz}$ \\
\hline
\end{tabular}

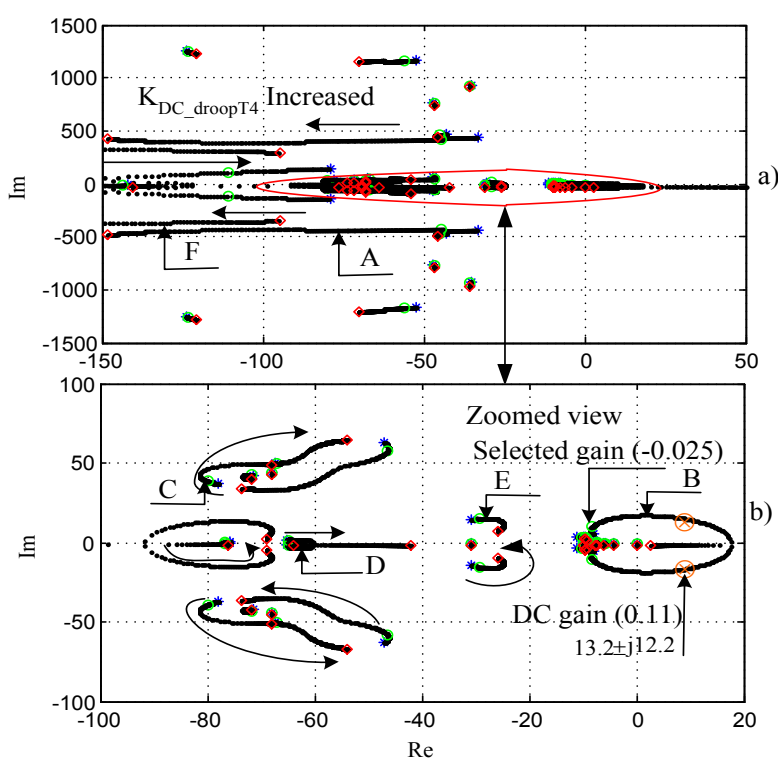

Figure 4. Root locus with variable $\mathrm{K}_{\mathrm{DC} \text { droopT4, }}\left(f_{D C \_ \text {droopT4 }}=30 \mathrm{~Hz}\right)$, DC voltage droop controls at terminals $\mathrm{T} 3, \mathrm{~T} 2, \mathrm{~T} 1$ are disabled

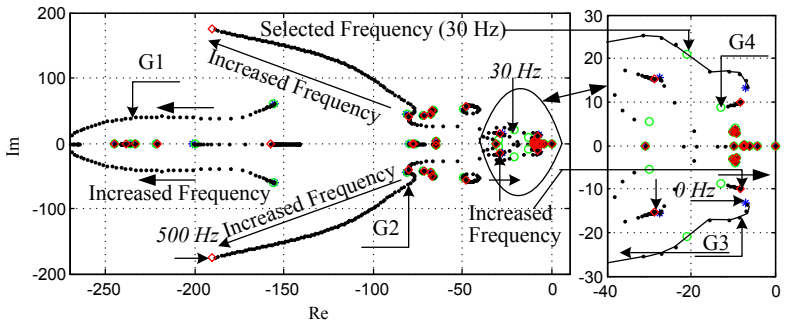

Figure 5. Root locus with variable $f_{D C \text { droopT4 }},\left(\mathrm{K}_{\mathrm{DC} \text { droopT4 }}=-0.025\right)$, the gains at other terminals are diseabled.

\section{B. Selection of de voltage droop control gains at terminal one (sending area)}

This section shows selection of the last droop gain, i.e that at terminal 1 . In this case the DC voltage droop gain $\left(K_{D C \text { droopTI }}\right)$ is varied with fixed cutoff frequency initially selected at $f_{D C \_ \text {droopTI }}=30 \mathrm{~Hz}$. The DC voltage droop gains and the cutoff frequency at the other terminals are represented in Table-A5. Fig. 6 illustrates root locus of the modeled system as function of $K_{D C}$ droopTl. It can be seen that the stability margin is generally improved as $K_{D C \text { droopTI }}$ increased but branch ' $\mathrm{M}$ ' crosses the imaginary axis and the system becomes unstable at higher gains.
Branch ' $M 2$ ' shows an improvement only for small values of DC droop gain. It is concluded that the best DC voltage droop gain at terminal one is 0.025 . These values for droop gains are in general agreement with static recommendations. Fig. 7 shows root locus as the cutoff frequency of the DC voltage droop control filter at terminal one $\left(f_{D C}\right.$ droopTl $)$ is changing from $0 \mathrm{~Hz}$ to $500 \mathrm{~Hz}$. It is noticed that the stability margin on branch ' $\mathrm{R}$ ' is decreased as $f_{D C \_ \text {droopTI }}$ while branches ' $R 1, R 2$ ' are showing an improvement as the $f_{D C_{-} \text {droop Tl }}$ increased. As a result the best value of cutoff frequency at terminal one is $30 \mathrm{~Hz}$.

Table-A5. DC voltage droop control gains

\begin{tabular}{|c|c|}
\hline DC droop gain & Cutoff frequency \\
\hline$K_{D C_{-} \text {droopT4 }}=-0.025(13.3 \%)$ & $f_{D C_{-} \text {droopT4 }}=30 \mathrm{~Hz}$ \\
\hline$K_{D C \_ \text {droopT3 }}=-0.025(13.3 \%)$ & $f_{D C_{-} \text {droop T3 }}=30 \mathrm{~Hz}$ \\
\hline$K_{D C_{-} \text {droopT } 2}=-0.025(13.3 \%)$ & $f_{D C \_ \text {droop T2 }}=30 \mathrm{~Hz}$ \\
\hline$K_{D C_{-} \text {droop } T 1}=0.025(13.3 \%)$ & $f_{D C_{-} \text {droopTI }}=30 \mathrm{~Hz}$ \\
\hline
\end{tabular}

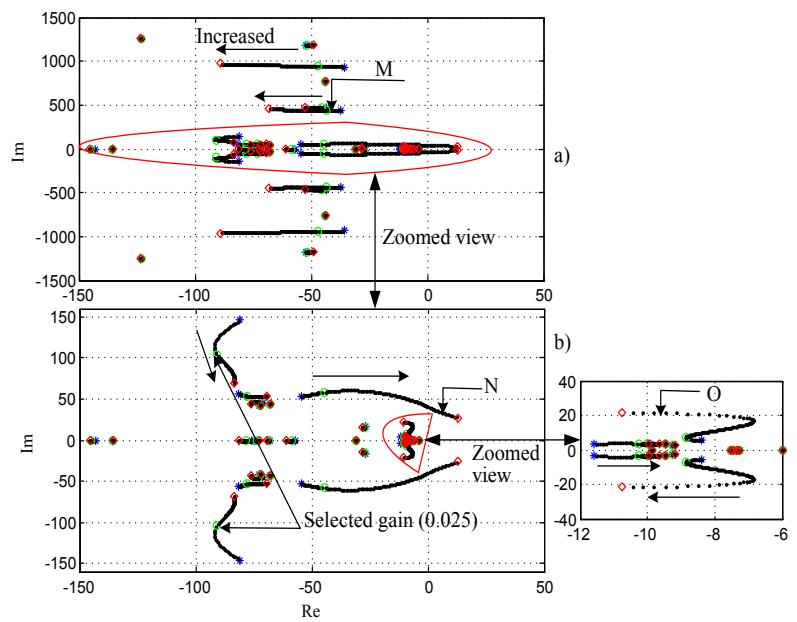

Figure 6. Root locus with variable, $\mathrm{K}_{\mathrm{DC} \_ \text {droop T1 }},\left(\mathrm{f}_{\mathrm{dc} \_ \text {droop1 }}=30 \mathrm{~Hz}\right)$, the gains at other terminals are given in Table-A5.

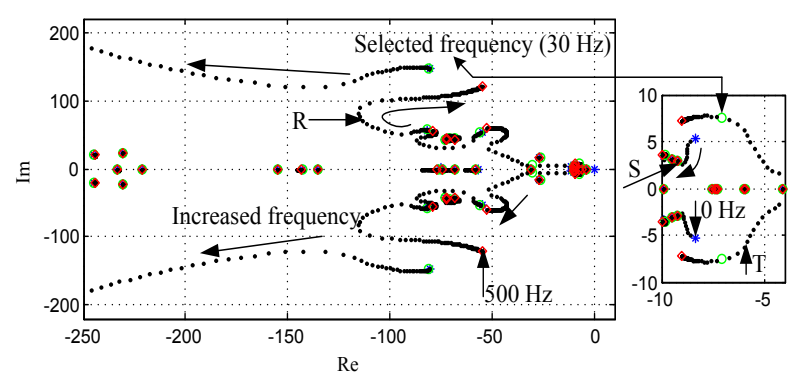

Figure 7. Root locus with variable $f_{D C_{\_} \text {droopTI }}, K_{D C_{-} \text {droop } T 1}=0.025$, the other droop gains are shown in Table-A4.

The above root locus plots show that it is generally very difficult to obtain stable performance for large DC voltage droop gains. In general, wider filter bandwidth improves stability but some high frequency instability can develop if too high cut-off frequency is employed. The root locus for the first terminal (terminal 4 in figure 4) is quite different from that for the last tuned terminal (terminal 1 in figure 6) 
which implies that droop gains have significant influence on the interaction between terminals.

\section{Robustness against AC system strength}

In contrast to the conventional HVDC transmission system, the VSC-HVDC system has the potential to be connected to very weak AC systems. Moreover, it has the capability to generate or consume reactive power depending on the operating conditions. In this section, the robustness of the implemented control system for DC grid network is investigated with and without DC droop control. This test ensures that in all operation conditions the system capable to remains stable and still gives satisfactory results for a range of AC grid strengths. In this case, the SCRT3 is varied from $20 \rightarrow 1$ with fixed $X_{-} T 3 / R_{A C T 3}=7$. Fig. 8a shows the eigenvalues of the $d$-axis current control without the DC voltage droop as AC system T3 strength is varied. Fig. $8 \mathrm{~b}$ demonstrates the performance of $d$-axis current control with the DC voltage droop control at all terminals. It is seen that DC voltage droop control improves stability of the overall system. In particular branch "x1" is shifted to the left when DC droop is employed. Also, this dominant branch is shorter when Dc droop is sued, which implies less sensitivity in performance. In general stability is better for stronger system.

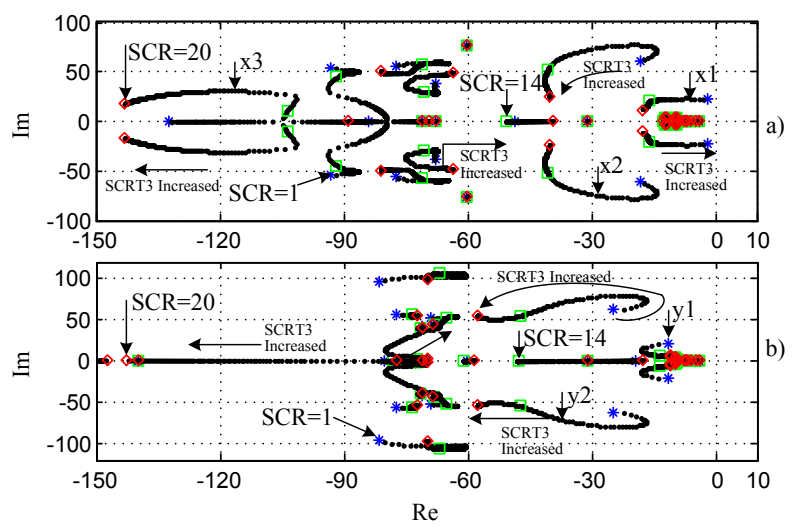

Figure 8. Root locus with changes in the system strength at terminal three, SCRT3 $(20 \rightarrow 1)$, a) without DC voltage droop control, b) with DC voltage droop control at all terminals.

\section{DC Network Model PSCAD Simulation}

\section{A. Step change on ac voltage reference at terminal five}

In all of the following studied scenarios, VSCT5 is adopted to control the DC voltage with the reference value equal to $300 \mathrm{kV}$. VSCT4, VSCT3, VSCT2, VSCT1 are adopted to regulate the d-axis current with DC voltage droop control. This section tests DC grid dynamic performance during steady state operation using a $5 \%$ step changes in $\mathrm{AC}$ voltage reference. Fig. 9a), shows the terminal $5 \mathrm{AC}$ voltage tracking without $\mathrm{DC}$ voltage droop control. Fig 9b) shows same variable when DC droop is used. The DC droop feedback does not have much influence on this variable as it is expected. Figure $9 \mathrm{c}$ and $9 \mathrm{~d}$ ) show the dynamic influence/disturbance on other systems variables and in this case DC droop much improves dynamics. It is evident that the step change in AC voltage at terminal five has created large transients on DC voltages at all terminals as presented in Fig. 9c. The use of droop feedback at all terminals significantly reduces DC voltage oscillations throughout the grid and enhances stability.

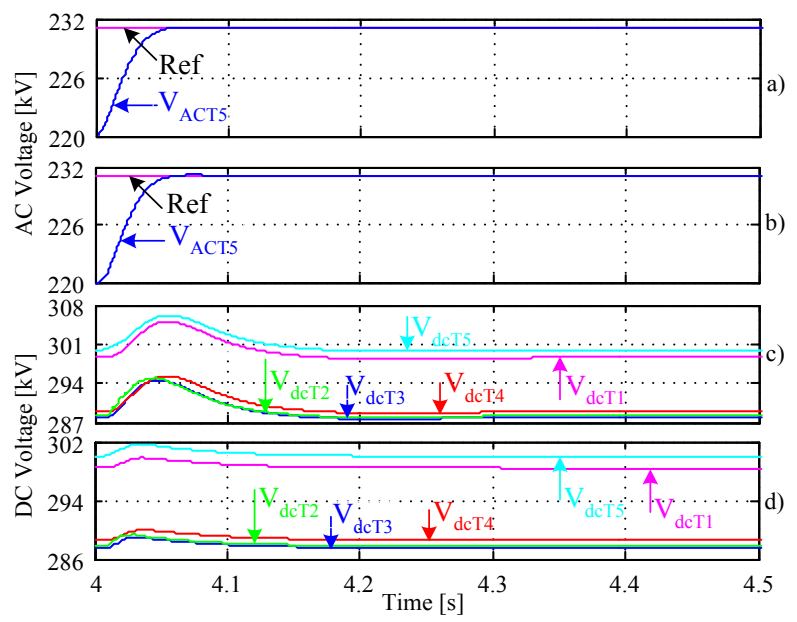

Figure 9. Test system performance for a $5 \%$ step on $\mathrm{AC}$ voltage reference $\mathrm{V}_{\mathrm{ACref} T 5}$ : a) AC voltage at terminal 5 -without $\mathrm{DC}$ voltage droop control, b) AC voltage at terminal 5 - with DC voltage droop control, c) Corresponding dynamic interaction on the DC voltages (T5, T4, T3, T2, and T2)- without DC voltage droop control, d) Corresponding dynamic interaction on the DC voltages (T5, T4, T3, T2, and T2)- with DC voltage droop control

\section{B. Impact of large DC droop gain on system performance}

The eigenvalue studies in previous sections suggest that the DC droop gain has a significant influence on system stability and that incorrectly tuned droop gains can lead to instability. To investigate that finding further, the DC droop gains for all terminals are increased (6 times corresponding to $2.2 \%$ ) while the rest of the gains and the parameters are kept unchanged. The time domain simulation is shown in Fig. 10. In this Fig. a 5\% step change on the $\mathrm{AC}$ voltage reference at terminals four, three, two and one is applied. It can be seen that the system becomes unstable when DC droop gains are high, which confirms the conclusions from eigenvalue study...

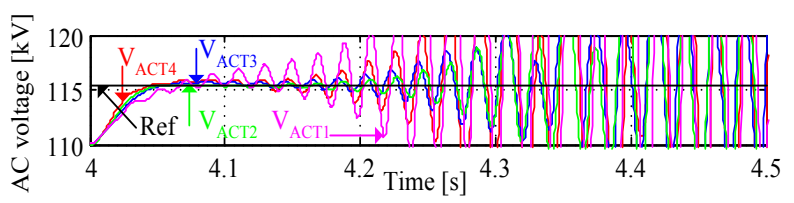

Figure 10. a 5\% step change on $\mathrm{AC}$ voltage reference at terminals four, three, two and one, with high DC voltage droop gain, $k_{D C_{-} \text {droopT4 }}=$ $k_{D C_{\_} \text {droop T3 }}=k_{D C_{\_} \text {droop T2 }}=-0.15, k_{D C_{-} \text {droopTI }}=0.15$, and $f_{D C_{-} \text {droop T4 }}=f_{D C_{-} \text {droop } T 3}=$ $f_{D C \_ \text {droopT2 }}=f_{D C \_ \text {droopT1 }}=30 \mathrm{~Hz}$ (PSCAD model) 


\section{Conclusions}

A small-signal $121^{\text {st }}$ order analytical model for detailed DC network based on VSC-HVDC is presented. The model is compared against detailed PSCAD simulation and it is concluded that the accuracy is good. The analytical model is suitable for eigenvalues studies of system stability and other dynamic analytical methods.

The advantages of the DC voltage droop control are explored analytically, using the small signal DC grid model, to plot the root locus as the values of DC droop gain and cutoff frequency of the DC voltage droop control filter are varied. It is established that the droop gain and the cutoff frequency of the DC voltage droop control have a significant impact on dynamic performance of DC grid. The stability analysis shows that it is very difficult to obtain stable performance for large DC voltage droop gains. Increasing the cutoff frequency of the DC voltage droop filter control in general improves performance but too wide bandwidth leads to lower stability margin.

The robustness analysis shows that control system with the DC voltage droop shows better performance with weak AC systems. The results from analytical studies are confirmed using detailed PSCAD model.

\section{Acknowledgements}

The author gratefully acknowledge support from professor D. Jovcic, School of Engineering, University of Aberdeen.

\section{REFERENCES}

[1] N. Flourentzou, V.G. Agelidis and G. D. Demetriades, "VSC-Based HVDC Power Transmission Systems: An Overview," IEEE Trans. Power Electronics, Vol. 24, No. 3, March 2009, pp. 592-602.

[2] Hairong Chen, Zheng Xu, Fan Zhang, "Nonlinear control for VSC based HVDC system," IEEE Power Engineering Society General Meeting, pp.1-5, 2006

[3] J L Thomas, S Poullain, A Benchaib, “Analysis of a robust DC-bus voltage control system for a VSC transmission scheme. Seventh International Conference on AC-DC Power Transmission (IEE Conf. Publ. No.485), IEE. 2001. London, $U K .$, pp.119-24

[4] H.F. Latorre, M. Ghandhari, L. Söder, "Active and reactive power control of a VSC-HVDC", Electric Power Systems Research, Volume 78, Issue 10, October 2008, Pages
$1756-1763$.

[5] D.Jovcic, L.A.Lamont, L.Xu, "VSC Transmission Model for Analytical Studies", Power Engineering Society General Meeting, 2003, IEEE, Vol. 3, Issue 13-17, July 2003 pp. 1742

[6] D.Jovcic N.Pahalawaththa, M.Zavahir "Small Signal Analysis of HVDC-HVAC Interactions" IEEE Transactions on Power Delivery, Vol. 14, no 2, April 1999, pp. 525-530.

[7] Adam G. P., Finney S. J., Williams B. W., Bell K., Burt G.: "Control of Multi-Terminal DC Transmission System Based on Voltage Source Converters", IET ACDC 2010, London, UK, 19-22 October 2010.

[8] J. Liang, O. Gomis-Bellmunt, J. Ekanayake, and N. Jenkins, "Control of multi-terminal VSC-HVDC transmission for offshore wind power," in Proc. 13th Eur. Conf. Power Electron. Appl., 2009, pp. 1-10.

[9] L. Xu, L. Yao, and M. Bazargan, "DC grid management of a multiterminal HVDC transmission system for large offshore wind farms," in Proc. Int. Conf. Sustainable Power Generation and Supply, 2009, pp. 1-7

[10] O. Gomis-Bellmunt, J. Liang, J. Ekanayake, R. King, and N. Jenkins, "Topologies of multiterminal HVDC-VSC transmission for large offshore wind farms," Electric Power Systems Research, on-line

[11] Alsseid, A.M.; Jovcic, D.; Starkey, A.," Small signal modelling and stability analysis of multiterminal VSC-HVDC," Power Electronics and Applications (EPE 2011), Proceedings of the 2011-14th European Conference on, vol., no., pp.1-10, Aug. 30 2011-Sept. 12011

[12] F. Katiraei and M. R. Iravani, "Power management strategies for a microgrid with multiple distributed generation units," IEEE Trans. On Power Systems, Vol. 21, No. 4, Nov. 2006, pp. 1821-1831

[13] M. N. Marwali, J. Jung, and A. Keyhani, "Control of distributed systems-part II: load sharing control," IEEE Trans. on Power Electronics, Vol. 19, No. 6, Nov. 2004, pp. 1551-1561.

[14] K. De Brabandere, B. Bolsens, J. Van den Keybus, A. Woyte, J. Driesen, and R. Belmans, "A voltage and frequency droop control method for parallel inverters," IEEE Trans. Power Electron., vol. 22, no. 4, pp. 1107-1115, Jul. 2007.

[15] Prieto-Araujo, E.; Bianchi, F. D.; Junyent-Ferre, A.; Gomis-Bellmunt, O., "Methodology for Droop Control Dynamic Analysis of Multiterminal VSC-HVDC Grids for Offshore Wind Farms," IEEE Transactions on Power Delivery, vol.26, no.4, pp.2476-2485, Oct. 2011

[16] W. Lu and B. Ooi, "DC overvoltage control during loss of converter in multiterminal voltage sourced converter based HVDC(M-VSC-HVDC)," IEEE Transactions on Power Delivery, vol. 18, no. 3, pp. 915-920, July 2003. 